\title{
Parâmetros Ruminais e Desaparecimento da FDN da Forragem em Bovinos Suplementados em Pastagem na Estação das Águas ${ }^{1}$
}

\author{
Gumercindo Loriano Franco 2 , Pedro de Andrade ${ }^{3}$, José Roberto Bruno Filho ${ }^{4}$, \\ José Mauro da Silva Diogo²
}

\begin{abstract}
RESUMO - O objetivo do presente trabalho foi determinar o efeito de suplementos concentrados com diferentes degradabilidades da proteína (alta-75\%, média-55\% e baixa-35\%) e o efeito da quantidade dos mesmos ( $0,5,1,0$ e 1,5 kg de MS/dia) sobre os parâmetros ruminais $\left(\mathrm{pH}\right.$ e $\mathrm{N}-\mathrm{NH}_{3}$ ) e o desaparecimento da FDN da forragem em bovinos pastejando Brachiaria brizantha cv. Marandu no período das águas. Foram utilizados dez bovinos canulados no rúmen com peso médio de $463 \mathrm{~kg}$ num esquema fatorial 3 x 3 com três repetições (blocos). A técnica do saco de náilon e a simulação do pastejo foram usadas para alcançar a cinética de degradação da FDN da forragem. Foram determinadas as concentrações $\mathrm{N}_{-} \mathrm{NH}_{3}$ e o pH ruminais durante dois dias, em vários horários. Não houve efeito dos suplementos, tampouco da quantidade destes sobre o desaparecimento da FDN da forragem, mas houve para os diferentes tempos de incubação, alcançando o potencial máximo de degradação $(67,58 \%)$ às 96 horas de incubação. $\mathrm{O}$ pH ruminal variou de 5,7 a 7,4 com média de 6,48, não havendo efeito de tratamento e nem interação tratamento x tempo. Já para os horários de determinação houve diferenças significativas. Para o $\mathrm{N}-\mathrm{NH}_{3}$ ruminal houve diferença significativa entre os tratamentos, sendo as maiores concentrações observadas para aqueles que apresentavam maior degradabilidade da proteína. Os primeiros horários após a suplementação apresentavam um maior pico de $\mathrm{N}_{-} \mathrm{NH}_{3}$ e os picos do período da manhã foram maiores que os da tarde. As diferentes concentrações de $\mathrm{N}-\mathrm{NH}_{3}$ ruminal não alteraram a degradação da fibra.
\end{abstract}

Palavras-chave: degradação, FDN, forrageiras tropicais, $\mathrm{N}-\mathrm{NH}_{3}$, proteína, saco de náilon

\section{Ruminal Parameters and NDF Forage Disappearance of Supplemented Steers under Grazing, during the Rainy Season}

\begin{abstract}
The objective this work was to evaluate the effect of protein supplements varying in ruminal degradabilities (high$75 \%$, medium-55\% and low-35\%) fed at three levels (0.5, 1.0 and $1.5 \mathrm{~kg} /$ day) on ruminal $\mathrm{pH}, \mathrm{N}-\mathrm{NH}_{3}$ and NDF degradability of forage, with steers grazing Brachiaria brizantha cv. Marandu during rainy season. The experiment design was a randomized complete block with three replications (grazing periods) and the supplemented treatments were arranged in a factorial $3 \times 3$. Ten rumen-fistuled crossbred steers with $463 \mathrm{~kg}$ live weight, were used. The nylon bag technique and grazing simulation were used to verify the forage and supplement ruminal degradation. Ruminal $\mathrm{pH}$ and $\mathrm{N}-\mathrm{NH}_{3}$ were determined along two consecutive days. There were no differences between the treatments (supplement source and level) on forage NDF degradability. However, there were differences for the incubation times, with the higher degradability $(67.58 \%)$ at 96 hours of incubation. No difference for the ruminal $\mathrm{pH}$ and time $\mathrm{x}$ treatment interaction were observed, but there were differences for the time of sampling. The $\mathrm{pH}$ varied ranged from 5.7 to 7.4 , with an average of 6.48 . The $\mathrm{N}$ $\mathrm{NH}_{3}$ values were higher for the supplements with high protein degradability. The first hours after supplementation showed the highest values of $\mathrm{N}-\mathrm{NH}_{3}$, and the peaks of $\mathrm{N}_{-} \mathrm{NH}_{3}$ in the morning were higher than the peaks of the afternoon. Fiber degradation was not affected by rumen $\mathrm{N}-\mathrm{NH}_{3}$ concentrations.
\end{abstract}

Key Words: degradability, NDF, $\mathrm{N}_{-} \mathrm{NH}_{3}$, nylon bag, protein, tropical forage

\section{Introdução}

No Brasil, consideráveis avanços na engorda de bovinos em pastagens têm sido observados nos últimos anos, fruto de ajustes nos procedimentos de suplementação concentrada dentro dos novos enfoques da nutrição de ruminantes, os quais se baseiam no adequado equilíbrio entre a utilização do nitrogênio e a matéria orgânica fermentável no rúmen. Assim, a maioria das justificativas para o melhor desempenho dos animais baseia-se no fato de que oferecendo-se proteína degradável no rúmen (PDR) aumenta-se o suprimento de amônia e energia, melhorando a síntese microbiana e consequentemente o desempenho animal (Paulino et al., 1995). Autores como Cochran et al. (1998) vão mais adiante,

\footnotetext{
1 Parte da Dissertação de Mestrado do primeiro autor apresentada à FCAV-UNESP, Campus de Jaboticabal. E.mail: glfranco@unb.br 2 Professor da Faculdade de Agronomia e Medicina Veterinária da Universidade de Brasília. E.mail: diogojm@unb.br

3 Professor Titular da FCAV-UNESP, Campus de Jaboticabal.

4 Zootecnista.
} 
enfatizando a importância da suplementação com PDR aliada a carboidratos disponíveis que permitirá um maior crescimento microbiano e fermentação, aumento da degradação da fibra e, consequentemente, da taxa de passagem e ingestão voluntária.

Segundo Ørskov \& Tyle (1990), os substratos disponíveis para fermentação juntamente com o pH ruminal são os principais fatores determinantes da prevalência dos microrganismos no ecossistema ruminal, destacando-se a redução do $\mathrm{pH}$ ruminal como a principal causa isolada de efeitos associativos negativos de diversos componentes da ração sobre a digestibilidade da ração.

A degradação das proteínas, peptídeos, aminoácidos e outras substâncias nitrogenadas promove a liberação de amônia para o líquido ruminal, que juntamente com a presença de carboidratos prontamente fermentáveis fornecendo energia (ATP) e carbono para a síntese da proteína microbiana, favorece a proliferação da microflora ruminal (Hungate, 1966). Os níveis de amônia no rúmen são importantes na síntese de proteína microbiana. Satter \& Roffler (1979) afirmaram que a concentração mínima de $\mathrm{N}_{-} \mathrm{NH}_{3}$ deve ser da ordem de $5 \mathrm{mg}$ de N$\mathrm{NH}_{3} / 100 \mathrm{~mL}$ de líquido ruminal para que a mesma não limite a fermentação microbiana, enquanto que para se atingir o máximo de síntese microbiana, Mehrez et al. (1977) preconizaram a concentração de $23 \mathrm{mg}$ de $\mathrm{N}-\mathrm{NH}_{3} / 100 \mathrm{~mL}$. Por outro lado, Boniface et al. (1987), citados por Morrison \& Mackie (1996), afirmaram que em bovinos consumindo forragem de baixa qualidade, a concentração de amônia que propicia a maximização da degradação da fibra, parece ser menor que aquela que maximiza a síntese de proteína microbiana e a ingestão de alimentos.

Segundo Owens \& Zinn (1988), existe variação na concentração de $\mathrm{N}-\mathrm{NH}_{3}$ nos horários após a alimentação, cuja intensidade depende do tipo de alimento. Com uréia, as concentrações máximas de $\mathrm{N}-\mathrm{NH}_{3}$ ocorrem entre 1 e 2 horas após seu fornecimento, enquanto rações ricas em proteína vegetal propiciaram o pico entre 3 e 4 horas após o consumo. A absorção de $\mathrm{N}-\mathrm{NH}_{3}$ ruminal aumenta à medida que eleva sua concentração no rúmen, passando a ser tóxica quando essa concentração ultrapassa valores da ordem de $100 \mathrm{mg} / 100 \mathrm{~mL}$.

Em novilhos de corte alimentados com feno de baixa qualidade e suplementados com farelo de algodão (800 g/dia), Mccollum \& Galyean (1985) observaram um pico de amônia uma hora após a suplementação, que foi consistentemente maior que em outros horários. Da mesma maneira, Caton et al. (1988), avaliando novilhos em pasto dormente, submetidos ou não à suplementação com farelo de algodão e grão de milho (45,5\% de PB), verificaram que a concentração de $\mathrm{N}-\mathrm{NH}_{3}$ ruminal foi maior em animais suplementados em horários próximos ao fornecimento do suplemento e com a tendência a ser maior estendendo-se até 8 horas após suplementação.

Na suplementação de bovinos com farelo de soja ou sorgo floculado com $0,5 \mathrm{~kg} / \mathrm{dia}$ em pastagem com $11,16 \%$ de PB, comparados a um testemunha sem suplementação, Krysl et al. (1989) observaram valores de $\mathrm{N}-\mathrm{NH}_{3}$ ruminal de 13,5, 8,7 e 9,9 mg/100 mL, respectivamente.

Com o objetivo de determinar qual o horário do dia em que ocorria maior pico de $\mathrm{N}-\mathrm{NH}_{3}$ ruminal, Judkins et al. (1991) trabalharam com novilhos oferecendo feno de festuca duas vezes ao dia (6 e 14 horas) e suplementaram com $1,084 \mathrm{~kg}$ de farelo de algodão em três horários (6, 10 e 14 horas). Os maiores picos de $\mathrm{N}-\mathrm{NH}_{3}(23,5,19,0$ e 15,0 mg/100 mL) ocorreram às 8 e 12 e 16 horas, ou seja, duas horas após o oferecimento dos suplementos, sendo que os picos de $\mathrm{N}-\mathrm{NH}_{3}$ na manhã eram maiores que os da tarde.

Franco et al. (1996) trabalhando com três níveis de degradabilidade da proteína (alta, média e baixa) e em três quantidades, suplementando bovinos no período da seca, encontraram que os níveis de $\mathrm{N}^{-\mathrm{NH}_{3}}$ ruminal $(17,0,21,9,27,9 \mathrm{mg} / 100 \mathrm{~mL})$, foram sensíveis à degradabilidade e à quantidade dos suplementos, de forma mais acentuada, uma hora após o fornecimento, declinando gradativamente até quatro a cinco horas. Entretanto, mesmo para o animal testemunha as concentrações de $\mathrm{N}_{-} \mathrm{NH}_{3}$ foram consideradas normais para crescimento dos microrganismos.

Com o objetivo de verificar o efeito da suplementação protéica sobre a degradação da fibra, Stokes et al. (1988) suplementaram com farelo de soja $(0,12$ ou $0,24 \%$ do peso vivo) vacas de corte recebendo ração à base de feno com $90 \%$ da ingestão ad libitum, constatando que a suplementação com PDR aumentou a digestibilidade da fibra em detergente neutro (FDN), porém com pequenas diferenças entre os dois níveis de proteína. Conforme Ortignes et al. (1988), em trabalho com uréia, uréia com palha ou uréia com milho, foi pequeno o impacto desse suplemento na extensão da digestão ruminal da FDN de feno de festuca de baixa qualidade.

De acordo com Galyean \& Owens (1991), a

\section{R. Bras. Zootec., v.31, n.6, p.2340-2349, 2002}


suplementação protéica em forragem com baixo teor de proteína e alto teor de fibra, melhora a digestão, subsequientemente melhorando a taxa de passagem e a ingestão voluntária. Todavia, estes resultados não são frequientemente registrados.

Avaliando diferenças no desaparecimento e na taxa de degradação da FDN do pasto, Krysl et al. (1989) suplementaram bovinos com $0,5 \mathrm{~kg}$ de farelo de soja ou $0,5 \mathrm{~kg}$ de grãos de sorgo floculados e não encontraram influência do carboidrato ou da proteína. Também Hunt et al. (1989) e Judkins et al. (1991) suplementaram com farelo de algodão novilhos que recebiam feno de festuca e não encontraram diferenças na taxa de desaparecimento da FDN, indicando que dependendo do tipo de suplemento não há modificação na degradação.

O objetivo deste experimento foi avaliar o efeito de suplementos concentrados com diferentes degradabilidades da proteína (alta, média e baixa) e fornecidos em três quantidades, sobre o $\mathrm{pH}, \mathrm{N}-\mathrm{NH}_{3}$ ruminal e desaparecimento da FDN em bovinos em pastejo no período das águas.

\section{Material e Métodos}

Este experimento foi conduzido na Faculdade de Ciências Agrárias e Veterinárias da Unesp, Campus de Jaboticabal, Estado de São Paulo, no período de janeiro a maio de 1996. Foram utilizados dez novilhos mestiços com peso vivo médio inicial de $463 \mathrm{~kg}$, providos de cânula permanente no rúmen, por onde foram fornecidos os suplementos e efetuadas as amostragens de líquido ruminal.

Os suplementos com diferentes degradabilidades da proteína $(35,55$ e $75 \%)$ foram obtidos pela combinação de alguns alimentos (Tabelas 1 e 2), sendo fornecidos nas quantidades de $0,5,1,0$ e $1,5 \mathrm{~kg}$ de MS/ animal/dia, o que correspondem a aproximadamente $0,11,0,22$ e $0,33 \%$ do peso vivo médio dos animais. Estes permaneciam em uma área de 2 hectares, formada com Brachiaria brizantha (Hochst ex A. Rich.) Stapf cv. Marandu, em estádio de crescimento vegetativo e com alta disponibilidade de forragem, (aproximadamente $4.500 \mathrm{~kg} \mathrm{MS} / \mathrm{ha}$ ), sendo utilizada em regime de lotação contínua durante todo o período. A amostragem da forrageira para incubação foi feita através da simulação de pastejo, conforme Euclides et al. (1992).

De acordo com os fundamentos para formulação de rações com proteína degradável no rúmen (PDR) e potencial de crescimento microbiano, expresso pela energia metabolizável fermentável (AFRC, 1993), o tratamento com proteína de média degradabilidade (55\%), oferecido na quantidade média (1 kg/animal/ dia) supriria a demanda microbiana, assumindo que a forragem possuía $10 \%$ de proteína bruta (PB), e serviu como referência em relação aos demais tratamentos. $\mathrm{O}$ suplemento foi fornecido via cânula, dividido em partes iguais, às 7 e $18 \mathrm{~h}$, juntamente com mistura mineral completa ( $35 \mathrm{~g} / \mathrm{animal} / \mathrm{alimentação).} \mathrm{O}$ animal testemunha só recebia a mistura mineral.

Houve um período de adaptação de 14 dias a ração, seguido de oito dias de coleta de dados, em três períodos experimentais. Após cada período, os animais eram ressorteados, mas não permitindo que recebessem o mesmo suplemento do período anterior e entravam num novo período de 14 dias de adaptação.

Para determinação da degradabilidade, foi utilizada a técnica do saco de náilon, onde os poros do tecido eram de aproximadamente $50 \mu \mathrm{m}$ de diâmetro, nas dimensões de 7 x $14 \mathrm{~cm}$, selados nas bordas por fusão com resistência elétrica e devidamente identificados. Após serem pesados, receberam $5 \mathrm{~g}$ da forrageira ou $5 \mathrm{~g}$ do suplemento, resultando em uma relação de $25 \mathrm{mg}$ de amostra por $\mathrm{cm}^{2}$ de área do saco de náilon.

Após o enchimento, cada saco teve sua extremidade selada, seu peso registrado e preso a uma argola de metal (de $1 \mathrm{~cm}$ de diâmetro), atado firmemente através de um elástico. Os sacos eram presos em

Tabela 1 - Participação (\% da MS) dos ingredientes nos suplementos protéicos com diferentes degradabilidades, fornecidos para bovinos em pastejo

Table 1 - Participation (\% of DM) of ingredients on supplements with different protein degradabilities fed grazing steers

\begin{tabular}{lccc}
\hline $\begin{array}{l}\text { Alimentos } \\
\text { Feedstuffs }\end{array}$ & \multicolumn{3}{c}{$\begin{array}{c}\text { Degradabilidade dos suplementos } \\
\text { Degradability of supplements }\end{array}$} \\
\cline { 2 - 4 } & $\begin{array}{c}\text { Alta } \\
\text { High }\end{array}$ & $\begin{array}{c}\text { Média } \\
\text { Medium }\end{array}$ & $\begin{array}{c}\text { Baixa } \\
\text { Low }\end{array}$ \\
\hline $\begin{array}{l}\text { Farelo de soja } \\
\text { Soybean meal }\end{array}$ & 29,3 & 17,8 & 6,7 \\
$\begin{array}{l}\text { Farelo de trigo } \\
\text { Wheat meal }\end{array}$ & 66,6 & - & - \\
$\begin{array}{l}\text { Milho } \\
\text { Corn }\end{array}$ & - & 60,8 & 49,5 \\
$\begin{array}{l}\text { Glutenose } \\
\text { Corn gluten meal }\end{array}$ & - & 17,4 & 43,8 \\
Uréia & & 4,0 & - \\
Urea & 4,1 & & \\
\hline
\end{tabular}


Tabela 2 - Composição química do pasto e dos suplementos protéicos com diferentes degradabilidades Table 2 - Chemical composition of the pasture and supplements with different protein degradabilities

\begin{tabular}{|c|c|c|c|c|c|c|c|c|c|}
\hline & \multirow[b]{2}{*}{$\begin{array}{l}\mathrm{MS} \\
D M\end{array}$} & \multicolumn{8}{|c|}{$\begin{array}{l}\% \mathrm{MS}^{1} \\
\% D M^{1}\end{array}$} \\
\hline & & $\begin{array}{l}\mathrm{MM} \\
M M\end{array}$ & $\begin{array}{l}\mathrm{PB} \\
C P\end{array}$ & $\begin{array}{l}\text { FB } \\
C F\end{array}$ & $\begin{array}{l}\mathrm{EE} \\
E E\end{array}$ & $\begin{array}{l}\text { ENN } \\
N N E\end{array}$ & $\begin{array}{l}\text { FDN } \\
N D F\end{array}$ & $\begin{array}{l}\text { FDA } \\
A D F\end{array}$ & $D^{*}$ \\
\hline $\begin{array}{l}\text { Forragem } 1 \\
\text { Forage } 1\end{array}$ & 113,2 & 9,7 & 10,3 & 25,6 & 2,5 & 51,9 & 69,5 & 34,5 & - \\
\hline $\begin{array}{l}\text { Forragem } 2 \\
\text { Forage } 2\end{array}$ & 15,3 & 8,2 & 9,4 & 28,7 & 2,7 & 51,0 & 72,2 & 35,9 & - \\
\hline $\begin{array}{l}\text { Forragem } 3 \\
\text { Forage } 3\end{array}$ & 17,5 & 9,5 & 9,0 & 29,0 & 2,5 & 50,0 & 72,1 & 36,8 & - \\
\hline $\begin{array}{l}\text { Alta (high) } \\
\text { Média (mean) } \\
\text { Baixa (low) }\end{array}$ & $\begin{array}{l}90,4 \\
89,4 \\
90,1\end{array}$ & $\begin{array}{l}5,7 \\
2,4 \\
17\end{array}$ & $\begin{array}{l}43,6 \\
41,1 \\
413\end{array}$ & $\begin{array}{l}7,4 \\
1,8 \\
1,3\end{array}$ & $\begin{array}{l}3,5 \\
3,7 \\
2,7\end{array}$ & $\begin{array}{l}39,8 \\
51,0 \\
53,0\end{array}$ & $\begin{array}{l}37,1 \\
20,0 \\
162\end{array}$ & $\begin{array}{r}11,8 \\
3,6 \\
3,5\end{array}$ & $\begin{array}{r}75 \\
55 \\
35\end{array}$ \\
\hline
\end{tabular}

* Degradabilidade (Degradability).

Forragems 1, 2 e 3, correspondem às amostras de pasto em nos períodos 1, 2 e 3.

${ }^{1}$ Matéria seca (MS), matéria mineral (MM), proteína bruta (PB), fibra bruta (FB), extrato etéreo (EE), extrato não nitrogenado (ENN), fibra em detergente neutro (FDN), fibra em detergente ácido.

Forages 1, 2 e 3 correspond to the sample of forage in the periods 1,2 e 3.

1 Dry matter (DM), matter mineral (MM), crude protein (CP), crude fiber (CF), ether extract (EE), free nitrogen extract (NNE), neutral detergent fiber (NDF), acid detergent fiber (ADF).

grupos de dois (forragem e suplemento) a uma argola de chaveiro, embebidos primeiramente em água por uma hora e presos a uma corrente de $50 \mathrm{~cm}$ ligada a uma âncora de 600 g. Em seguida eram introduzidos no rúmen via cânula, na ordem inversa dos horários de incubação (120, 96, 72, 48, 24, 12, 6, 3 horas) de modo a serem retirados todos de uma só vez. Dessa forma, foram incubados 16 sacos por animal e oito sacos (somente forragem) no testemunha.

Retirados do rúmen, os sacos eram imediatamente imersos em água fria e lavados manualmente em água corrente até que esta escorresse límpida e em seguida, colocados em estufa de ventilação forçada de ar, a $55^{\circ} \mathrm{C}$, onde permaneciam por 48 horas, para posterior esfriamento e pesagem.

O procedimento para a determinação da fração solúvel consistiu em colocar em sacos de náilon a mesma quantidade de amostra utilizada para incubação, fechá-los e colocá-los em banho-maria por uma hora a $38^{\circ} \mathrm{C}$, lavá-los em água corrente da mesma forma que os incubados e submetendo-os à secagem em estufa. A perda de peso foi considerada a fração solúvel (fração “ $a$ ” do modelo de Merhez et al., 1977).

A fração "degradação potencial” foi considerada aquela onde se estabilizou a degradação do substrato no decorrer dos horários de incubação. Para o cálculo da taxa de degradação por hora, fração " $c$ ", subtraíram-se da fração potencialmente degradável a parte solúvel (fração " $a$ ") e a insolúvel (parte não degradada). A estes resultados foi aplicado o logaritmo neperiano
"In" e depois feita uma regressão linear simples, utilizando-se os horários de incubação para os valores de " $x$ " e o "ln" dos valores de degradação para " $y$ ". A fração " $c$ " foi considerada como o valor da inclinação da reta obtida.

O tempo de colonização foi calculado com os resultados de inclinação e intercepto obtidos pela regressão, juntamente com o "ln" obtido da respectiva fração potencialmente degradável conforme, Huntington \& Givens (1995).

As amostras de líquido ruminal foram coletadas no segundo e terceiro dias após a retirada dos sacos de náilon. No segundo dia coletou-se às 7 horas (antecedendo a suplementação), 8, 12, 16, 20, 0, 4 horas, e no terceiro dia, às $10,14,18$ (antes da suplementação), 19, 22, 2 e 6 horas.

A rotina obedeceu sempre a mesma sequência dos animais, sendo feita uma coleta em vários pontos do rúmen, formando uma amostra de aproximadamente $2 \mathrm{~kg}$, que era espremida através de saco de pano duplo para coleta de duas amostras de $50 \mathrm{~mL}$, visando a determinação de $\mathrm{pH}$ e $\mathrm{N}-\mathrm{NH}_{3}$ ruminal. $\mathrm{O}$ resíduo devolvia-se ao rúmen do animal.

$\mathrm{O}$ pH das amostras era medido imediatamente após a coleta do líquido, enquanto o $\mathrm{N}-\mathrm{NH}_{3}$ ruminal era determinado posteriormente. Para isso, as amostras eram acidificadas com 3 gotas de $\mathrm{H}_{2} \mathrm{SO}_{4}$ concentrado de forma que o $\mathrm{pH}$ ficasse abaixo de $5,5 \mathrm{e}$ rapidamente congeladas. Ao final do experimento, as amostras foram descongeladas e a concentração de 
$\mathrm{N}-\mathrm{NH}_{3}$ obtida após destilação com KOH $2 \mathrm{~N}$, segundo técnica descrita por Fenner em 1965, adaptada por Vieira (1980).

As análises estatísticas das variáveis foram realizadas segundo o programa SAS (1985), sendo utilizado o seguinte modelo estatístico para a análise do fatorial:

$\mathrm{Yijkl}=\mu+\mathrm{Bi}+\mathrm{Dj}+\mathrm{Nk}+\mathrm{B}(\mathrm{DxN}) \mathrm{i}(\mathrm{jk})+\mathrm{tl}+$

$(\mathrm{DxT}) \mathrm{jl}+(\mathrm{NxT}) \mathrm{kl}+(\mathrm{DxNxT}) \mathrm{jkl}+\mathrm{lijkl}$,

em que: $Y i j k l=$ valor observado para $Y$, no $\mathrm{i}-$ ésimo bloco, na j-ésima ração, no k-ésimo nível, no l-ésimo tempo; $\mu=$ média geral; $\mathrm{Bi}=$ efeito de bloco $(\mathrm{i}=1,2,3) ; \mathrm{Dj}=$ efeito de ração $(\mathrm{j}=1,2,3) ; \mathrm{Nk}=$ efeito de nível $(\mathrm{k}=1,2,3) ; \mathrm{B}(\mathrm{DxN}) \mathrm{i}(\mathrm{jk})$ (resíduo a) = efeito do i-ésimo bloco dentro da interação entre j-ésima ração no k-ésimo nível; $\mathrm{tl}$ = efeito do tempo para $\mathrm{pH}$ e N-NH $\mathrm{NH}_{3}(1=1,2, \ldots \ldots .14)_{;} \mathrm{FDN}(1=1,2, \ldots 8)$; $(D x T) j l=$ efeito da interação entre j-ésima ração e l-ésimo tempo; $(\mathrm{NxT}) \mathrm{kl}=$ efeito da interação entre k-ésimo nível e l-ésimo tempo; $(\mathrm{DxNxT}) \mathrm{jkl}=$ efeito da interação entre j-ésimo ração, k-ésimo nível e l-ésimo tempo; eijkl = erro associado à observação ijk (resíduo B).

Para comparação do fatorial com a testemunha também foi utilizado o SAS (1985), com o seguinte modelo estatístico:

$Y i j k=\mu+B i+T j+(B T) i j+t k+(T t) j k+e i j k$ em que: $\mathrm{Yijkl}=$ valor observado para $\mathrm{Y}$, no i-ésimo bloco, na j-ésima ração, no k-ésimo nível, no l-ésimo tempo; $\mu=$ média geral; $\mathrm{Bi}=$ efeito de bloco $(\mathrm{i}=1,2,3)$; $\mathrm{Tj}=$ efeito de tratamento $(\mathrm{j}=1,2,3, \ldots . .10) ;(\mathrm{BT}) \mathrm{ij}=$ efeito da interação entre o i-ésimo bloco e o j-ésimo tratamento; tk = efeito do tempo para $\mathrm{pH}$ e $\mathrm{N}-\mathrm{NH}_{3}$ $(1=1,2, \ldots . .14) ; \mathrm{FDN}(1=1,2, \ldots 8) ;(\mathrm{Tt}) \mathrm{jk}=$ efeito da interação entre o j-ésimo tratamento e o k-ésimo tempo; eijk = erro associado à observação ijk (resíduo B).

\section{Resultados e Discussão}

Os resultados de desaparecimento da proteína bruta (PB) dos suplementos encontram-se na Tabela 3. Houve diferença significativa $(\mathrm{P}<0,05)$ entre os suplementos incubados tanto para a matéria seca (MS) como para PB, assim como para os diferentes horários de incubação. Entretanto, não observou-se diferença $(\mathrm{P}>0,05)$ entre os níveis de suplementação e nem para a interação ração e nível. A proteína do suplemento apresentou degradação maior que a calculada a partir dos dados das tabelas internacionais, o que não comprometeu o objetivo do ensaio, resultado que comprova diferença $(\mathrm{P}<0,05)$ entre as
Tabela 3 - Desaparecimento da proteína bruta (PB) do suplemento (\%) no rúmen de bovinos em pastejo, obtido com suplemento protéico de diferentes degradabilidades

Table 3 - Disappearance of crude protein $(C P)$ from supplement (\%) in the rumen of steers in pasture, under protein supplements of different degradabilities

\begin{tabular}{|c|c|c|c|c|}
\hline \multirow[b]{2}{*}{$\begin{array}{l}\text { Horários } \\
\text { Times }\end{array}$} & \multicolumn{3}{|c|}{$\begin{array}{l}\text { Ração } \\
\text { Ration }\end{array}$} & \multirow[b]{2}{*}{$\begin{array}{c}\text { Médias } \\
\text { Means }\end{array}$} \\
\hline & $\begin{array}{l}\text { Alta } \\
\text { High }\end{array}$ & $\begin{array}{l}\text { Média } \\
\text { Medium }\end{array}$ & $\begin{array}{l}\text { Baixa } \\
\text { Low }\end{array}$ & \\
\hline 3 & 61,62 & 46,32 & 23,50 & $43,81 \mathrm{a}$ \\
\hline 6 & 69,91 & 49,39 & 30,76 & $50,02 \mathrm{~b}$ \\
\hline 12 & 84,10 & 58,46 & 32,85 & $58,35 \mathrm{c}$ \\
\hline 24 & 95,51 & 69,71 & 43,84 & $69,69 d$ \\
\hline 48 & 97,34 & 77,78 & 58,70 & $77,94 \mathrm{e}$ \\
\hline 72 & 98,23 & 89,91 & 76,86 & $88,83 \mathrm{f}$ \\
\hline $\mathrm{N}^{\mathrm{o}}$ obs. & 54 & 51 & 52 & \\
\hline Médias & $84,45 a$ & $64,05 b$ & $44,06 \mathrm{c}$ & \\
\hline
\end{tabular}

Médias nas colunas ou linhas seguidas de letras diferentes diferem entre si $(P<0,05)$.

Means withina column or row with different letters differ $(p<.05)$.

degradabilidades dos suplementos. Em todos os horários de incubação, as rações foram diferentes para todos os tempos de incubação quanto à degradação da proteína do suplemento.

Para o $\mathrm{pH}$ ruminal não houve diferença significativa $(P>0,05)$ entre os tratamentos, bem como não houve efeito $(\mathrm{P}>0,05)$ da interação tratamento e horário de avaliação (Tabela 4). Entretanto, com relação aos horários de determinação de $\mathrm{pH}$ houve diferença significativa $(\mathrm{P}<0,01)$, sendo que às 8 horas observou-se o maior valor e à 0 hora o menor. Nas 420 amostras analisadas, o pH variou de 5,27 a 7,40, com média de 6,48 .

De acordo com Coelho da Silva \& Leão (1979), para um ambiente ruminal normal, o $\mathrm{pH}$ deve ficar entre 5,5 e 7,0, valores que, comparados aos obtidos no presente trabalho (Figura 1), permitem concluir que os resultados se encontraram dentro de uma faixa normal para rações ricas em carboidratos estruturais. Relacionando os resultados aqui observados com aqueles da concentração de $\mathrm{N}-\mathrm{NH}_{3}$ ruminal (Figura 2), verifica-se que houve um sincronismo entre os horários de maior $\mathrm{pH}$ com os de maior concentração de $\mathrm{N}^{-\mathrm{NH}_{3}}$ ruminal. Isto sugere que existe uma relação entre horários de suplementação e $\mathrm{pH}$ ruminal.

Mccollum \& Galyean (1985) não encontraram diferenças de $\mathrm{pH}$ nos diversos horários de coleta e nem dos suplementados em relação ao controle, este

R. Bras. Zootec., v.31, n.6, p.2340-2349, 2002 


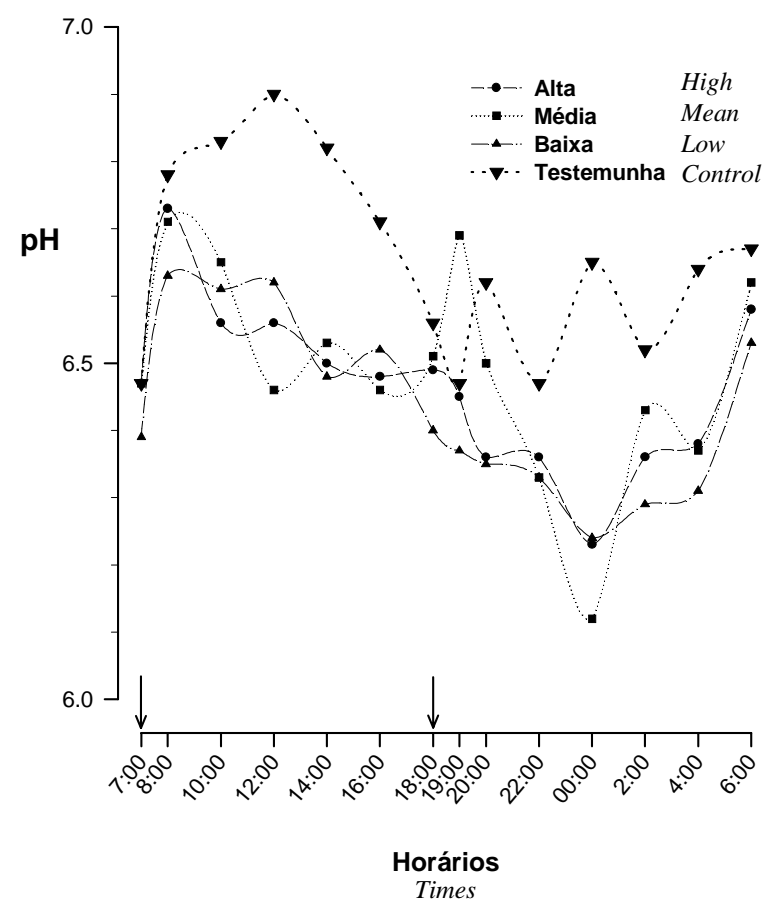

Figura 1 - Variação do pH ruminal obtidos com suplemento protéico de diferentes degradabilidades fornecidos para bovinos em pastejo.

Figure 1 - Variation in ruminal pH obtained with protein supplements of different degradabilities fed steers under grazing.

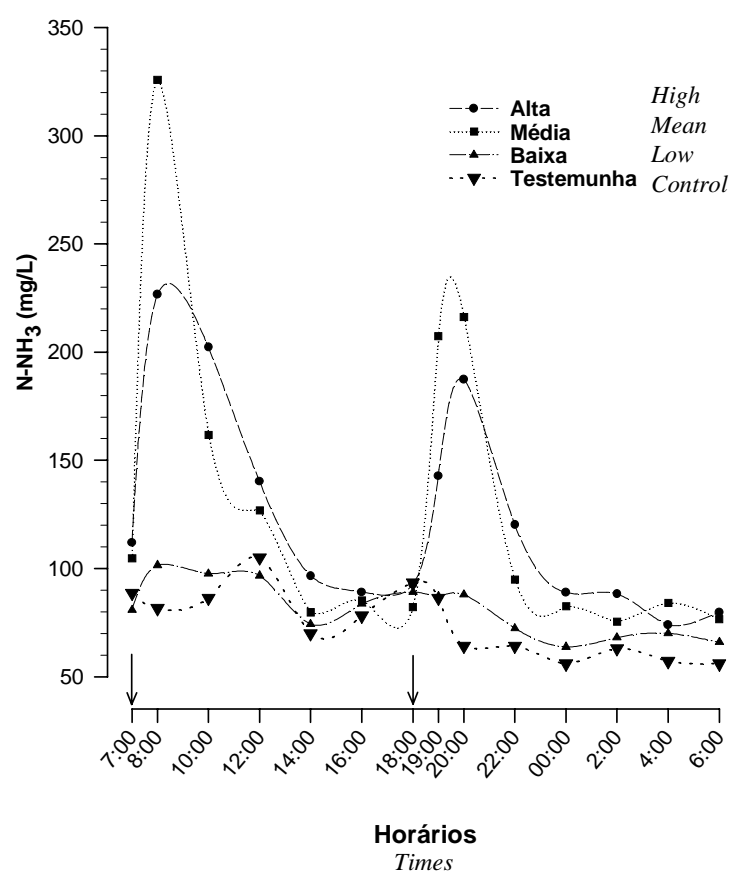

Figura 2 - Variação do $\mathrm{N}-\mathrm{NH}_{3}$ ruminal obtidos com suplemento protéico de diferentes degradabilidades fornecidos para bovinos em pastejo.

Figure 2 - Variation in ruminal $\mathrm{N}-\mathrm{NH}_{3}$ obtained with protein supplements of different degradability and fed steers under grazing.
Tabela 4 - Valores médios de $\mathrm{pH}$ ruminal obtidos com suplemento protéico de diferentes degradabilidades e fornecidos em diferentes quantidades para bovinos em pastejo

Table 4 - Mean ruminal $\mathrm{pH}$ values obtained with protein supplements of different degradabilities and fed in different quantities for steers in pasture

\begin{tabular}{lccc}
\hline & \multicolumn{3}{c}{$\begin{array}{c}\text { Degradabilidade } \\
\text { Degradability }\end{array}$} \\
\cline { 2 - 4 } Quantidades (kg MS) & Alta & Média & Baixa \\
Amounts (kg DM) & High & Medium & Low \\
\hline 0,5 & 6,99 & 6,39 & 6,44 \\
1,0 & 6,38 & 6,46 & 6,79 \\
1,5 & 6,33 & 6,62 & 6,08 \\
Testemunha & & 6,65 & \\
Control & & & \\
\hline
\end{tabular}

último também observado por Franco et al. (1996) e Krysl et al. (1989) que encontraram valores variando de 6,2 a 6,5 .

Já para o N-NH $\mathrm{NH}_{3}$ ruminal, observando-se a Tabela 5 percebe-se que houve diferença significativa $(\mathrm{P}<0,05)$ entre os tratamentos. Aqueles que apresentavam maior degradabilidade da proteína tiveram maiores médias de concentração de $\mathrm{N}-\mathrm{NH}_{3}$ ruminal e aqueles com menor degradabilidade, juntamente com o testemunha, as menores médias. Os resultados de $\mathrm{N}-\mathrm{NH}_{3}$ ruminal para as 420 amostras analisadas tiveram amplitude de 3,15 a 71,75 , ficando na média com $10,78 \mathrm{mg}$ de $\mathrm{N}-\mathrm{NH}_{3} / 100 \mathrm{~mL}$ de líquido ruminal. 
Tabela 5 - Valores médios de $\mathrm{N}-\mathrm{NH}_{3}$ ruminal obtidos com suplemento protéico de diferentes degradabilidades e fornecidos em diferentes quantidades para bovinos em pastejo

Table 5 - Mean ruminal $\mathrm{N}-\mathrm{NH}_{3}$ values obtained with protein supplements of different degradabilities and given in different quantities to steers on pasture

\begin{tabular}{lc}
\hline $\begin{array}{l}\text { Tratamentos } \\
\text { Treatments }\end{array}$ & $\mathrm{N}^{1,2} \mathrm{NH}_{3} \mathrm{mg} / \mathrm{L}$ \\
\hline MQ3 & $169,3 \mathrm{a}$ \\
AQ2 & $154,1 \mathrm{ab}$ \\
AQ3 & $139,2 \mathrm{abc}$ \\
MQ2 & $121,2 \mathrm{abcd}$ \\
MQ1 & $95,8 \mathrm{bcd}$ \\
BQ3 & $92,6 \mathrm{bcd}$ \\
BQ2 & $81,6 \mathrm{~cd}$ \\
AQ1 & $79,6 \mathrm{~cd}$ \\
Testemunha & $73,7 \mathrm{~cd}$ \\
Control & \\
BQ1 & $71,1 \mathrm{~d}$ \\
\hline
\end{tabular}

Médias nas colunas seguidas de letras diferentes diferem entre si $(\mathrm{P}<0,05)$.

Means within a column followed by different letters differ $(p<.05)$.

${ }^{1} \mathrm{~A}$, Alta (high); M, Média (medium); B, Baixa (low).

${ }^{2} \mathrm{Q} 1,0,5 ; \mathrm{Q} 2,1,0 ; \mathrm{Q} 3,1,5 \mathrm{~kg} / \mathrm{animal} / \mathrm{dia}$ (kg/cattle/day).

Para os diferentes horários de determinação de $\mathrm{N}-\mathrm{NH}_{3}$ ruminal após a suplementação, a Figura 2 mostra que os primeiros horários após a suplementação apresentaram um maior pico de $\mathrm{N}-\mathrm{NH}_{3}$ ruminal, havendo interação $(\mathrm{P}<0,05)$ entre tratamento e tempo. O desdobramento da interação indicou que o tratamento representado pelo suplemento de média degradabilidade (55\% PDR), oferecido na quantidade de $1,5 \mathrm{~kg}$ proporcionou um $\mathrm{N}-\mathrm{NH}_{3}$ ruminal de $487,7 \mathrm{mg} / \mathrm{L}$ às 8 horas ( 1 hora após a suplementação), sendo significativamente superior $(\mathrm{P}<0,05)$ aos outros suplementos e suas quantidades nos demais horários. Neste mesmo horário (8 horas), o suplemento de alta degradabilidade (75\% PDR), fornecido a base de $1 \mathrm{~kg}$ foi o que proporcionou o segundo maior valor $(357 \mathrm{mg} / \mathrm{L})$, porém não se diferenciou $(\mathrm{P}>0,05)$ do valor obtido às 10 horas $(252 \mathrm{mg} / \mathrm{L})$. Também às 8 horas, o suplemento de média degradabilidade proporcionou valores de 231 e $258,8 \mathrm{mg} / \mathrm{L}$ nas quantidades de 0,5 e $1 \mathrm{~kg}$, respectivamente, sendo que o ultimo não se diferenciou ( $\mathrm{P}>0,05)$ do valor de $156,3 \mathrm{mg} / \mathrm{L}$ verificado às 10 horas, tampouco dos resultados obtidos para $\mathrm{o}$ suplemento de alta degradabilidade com $1,5 \mathrm{~kg} / \mathrm{dia}$ às 8,10 e 12 horas, $157,5,245$ e $176 \mathrm{mg} / \mathrm{L}$, respectivamente. A partir de 8-10 horas até à tarde, não houve diferença $(P>0,05)$ entre os demais suplementos e quantidades, e entre os horários de coleta.

Logo após a suplementação da tarde, foi verificado o mesmo comportamento de picos de $\mathrm{N}-\mathrm{NH}_{3}$ ruminal observado após a suplementação da manhã, mas com menores concentrações. O suplemento de média degradabilidade (55\% PDR) oferecido na quantidade de $1,5 \mathrm{~kg} /$ dia proporcionou $351,2 \mathrm{mg} / \mathrm{L}$ de N$\mathrm{NH}_{3}$ ruminal, sendo significativamente diferente $(\mathrm{P}<0,05)$ dos demais suplementos e horários. Os valores de $\mathrm{N}-\mathrm{NH}_{3}$ ruminal do suplemento de alta degradabilidade (75\% PDR) nas quantidades de $1 \mathrm{e}$ $1,5 \mathrm{~kg} /$ dia e do suplemento de média degradabilidade nas quantidades de 0,5 e $1 \mathrm{~kg} /$ dia foram de 199,8, $143,5,128,3$ e $142,3 \mathrm{mg} / \mathrm{L}$, respectivamente, não sendo significativamente diferentes $(\mathrm{P}<0,05)$.

A Figura 2 mostra claramente que as maiores concentrações de $\mathrm{N}_{-} \mathrm{NH}_{3}$ ruminal ocorreram às $8 \mathrm{e}$ posteriormente às 20 horas, confirmando assim as informações de Owens \& Zinn (1988), Mccollun \& Gaylean (1985) e Franco et al. (1996), que também encontraram maiores concentrações de $\mathrm{N}_{-} \mathrm{NH}_{3}$ ruminal 2 horas após a suplementação, atribuindo-se à solubilidade das fontes protéicas. No presente ensaio, os resultados observados para o $\mathrm{N}^{-\mathrm{NH}_{3}}$ ruminal com os suplementos de média degradabilidade (55\% PDR) foram maiores que as de alta $(75 \%$ PDR), resultados estes, aparentemente contraditórios quando comparados àqueles obtidos pelos autores anteriormente citados.

Estes resultados já eram esperados, tendo em vista que a colocação do suplemento diretamente no rúmen solubilizou com mais rapidez a proteína, o que faz pressupor que o pico de $\mathrm{N}-\mathrm{NH}_{3}$ ruminal ocorreu com menos de 1 hora após o fornecimento do suplemento.

Judkins et al. (1991) também encontraram maiores concentrações de $\mathrm{N}_{-} \mathrm{NH}_{3}$ ruminal nos horários da manhã que nos da tarde, e no presente experimento concentrações de $\mathrm{N}^{-\mathrm{NH}_{3}}$ ruminal do animal testemunha também apresentou picos de $\mathrm{N}-\mathrm{NH}_{3}$ ruminal nos mesmos horários que os animais suplementados, permitindo inferir que os picos de $\mathrm{N}-\mathrm{NH}_{3}$ ruminal também estão relacionados com os horários de pastejo o que vem concordar com as informações de Van Soest (1994).

Os valores médios encontrados em cada tratamento, bem como a média dos valores de todas as observações estão acima do valor limitante da fermentação ruminal ( $5 \mathrm{mg} / \mathrm{L}$ de $\mathrm{N}-\mathrm{NH}_{3}$ ) considerado por Satter \& Roffler (1979), indicando desta forma que o $\mathrm{N}-\mathrm{NH}_{3}$ ruminal não limitou o crescimento microbiano em nenhum dos tratamentos. 
Já para maximização da fermentação ruminal o valor médio e algumas concentrações, embora não significativas, estão abaixo de $230 \mathrm{mg} / \mathrm{L}$ de $\mathrm{N}^{-N_{3}}$ ruminal recomendadas por Mehrez et al. (1977), o que poderia refletir negativamente na degradação da fibra da forragem.

Pela Figura 3 evidencia-se o desaparecimento significativo $(\mathrm{P}<0,05)$ da fibra em detergente neutro (FDN) em relação ao tempo, porém, não havendo diferença $(\mathrm{P}>0,05)$ entre os suplementos ou suas interações com o tempo (Tabela 6). Este comportamento contraria um paradigma da nutrição dos ruminantes, no qual o aumento de PDR elevaria o crescimento microbiano acelerando a degradação da fibra e demais componentes da forragem e, por conseqüência, a taxa de passagem e a ingestão voluntária como verificaram Ortignes et al. (1988), Stokes et al. (1988) e Galyean \& Owens (1991) que encontraram efeito da suplementação protéica ou da ração na degradação da fibra. Já outros autores como Gierus et al. (1995) e Sprag et al. (1996), não encontraram diferenças na degradação da fibra com animais suplementados.

Para a degradação potencial da fibra, taxa de degradação e tempo de colonização $(67,58 \%, 5,77 \%$ / hora e 6,15 horas) não foram encontradas diferenças $(\mathrm{P}>0,05)$ entre os tratamentos (suplementos e quantidades $)$ mas sim entre períodos $(\mathrm{P}<0,05)$ para a fração "b" da fibra, devido ao avanço na maturidade do pasto e efeito do pastejo. O coeficiente de variação para o desaparecimento da fibra foi de $8,99 \%$.

Judkins et al. (1991), trabalhando com festuca, encontraram taxas de desaparecimento da fibra de

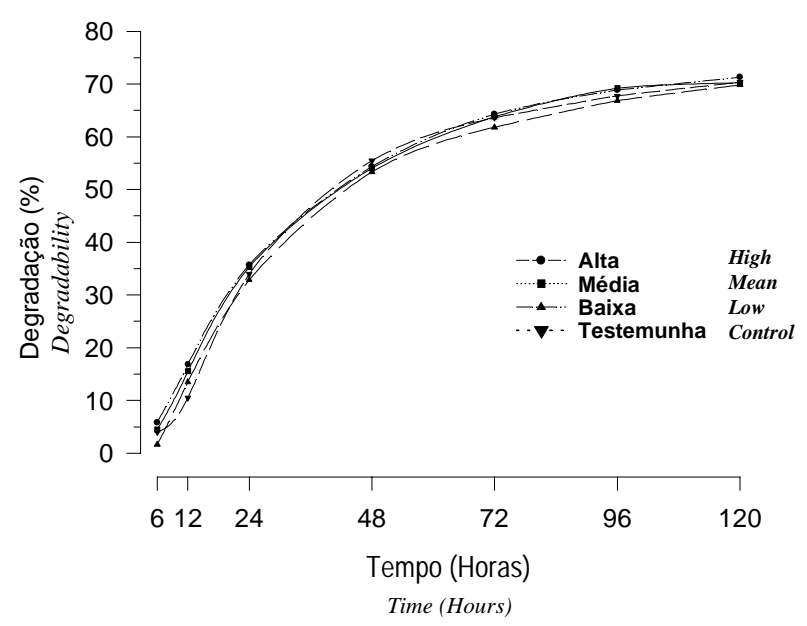

Figura 3 - Desaparecimento da fibra em detergente neutro do pasto (\%) no rúmen de bovinos em pastejo, obtido com suplemento protéico de diferentes degradabilidades.

Figure 3 - Disappearance of neutral detergent fiber in the pasture (\%) in the rumen of steers in pasture under protein supplements of different degradability fed steers under grazing.

\begin{tabular}{|c|c|c|c|c|c|}
\hline \multirow[b]{2}{*}{$\begin{array}{l}\text { Horários } \\
\text { Times }\end{array}$} & \multicolumn{4}{|c|}{$\begin{array}{l}\text { Ração } \\
\text { Ration }\end{array}$} & \multirow[b]{2}{*}{$\begin{array}{l}\text { Médias } \\
\text { Means }\end{array}$} \\
\hline & $\begin{array}{l}\text { Alta } \\
\text { High }\end{array}$ & $\begin{array}{l}\text { Média } \\
\text { Medium }\end{array}$ & $\begin{array}{l}\text { Baixa } \\
\text { Low }\end{array}$ & $\begin{array}{c}\text { Testemunha } \\
\text { Control }\end{array}$ & \\
\hline 6 & 4,46 & 1,62 & 3,99 & 5,86 & $3,60 \mathrm{a}$ \\
\hline 12 & 15,51 & 13,49 & 10,52 & 16,83 & $13,54 b$ \\
\hline 24 & 35,33 & 32,83 & 33,95 & 35,74 & $34,21 \mathrm{c}$ \\
\hline 48 & 54,03 & 53,35 & 55,46 & 54,34 & $54,30 \mathrm{~d}$ \\
\hline 72 & 63,79 & 61,81 & 63,60 & 64,29 & $63,39 \mathrm{e}$ \\
\hline 96 & 69,20 & 66,83 & 67,74 & 68,84 & $68,20 \mathrm{f}$ \\
\hline 120 & 70,25 & 69,81 & 70,34 & 71,29 & $70,25 f$ \\
\hline $\mathrm{N}^{\circ}$ obs. & 61 & 62 & 63 & 21 & \\
\hline Médias & $43,71 \mathrm{a}$ & $42,54 a$ & $42,33 a$ & $45,31 \mathrm{a}$ & \\
\hline Means & & & & & \\
\hline
\end{tabular}

R. Bras. Zootec., v.31, n.6, p.2340-2349, 2002 
3,24\%/hora, enquanto Hess et al. (1994) de 2,6\%/ hora, com degradação potencial às 96 horas de $53,1 \%$. Já Hunt et al. (1989), Krysl et al. (1989) e Caton et al. (1988) também trabalharam com suplementos, mas assim como os autores anteriormente mencionados, não encontraram influência da suplementação sobre as taxas de degradação da fibra.

Já em relação aos valores absolutos, Gupta et al. (1996) encontraram para degradação potencial, taxa de degradação e tempo de colonização de aveia e azevém, respectivamente, 100 e $94 \%$; 4,96 e 6,84\%/hora e 4,3 e 6,7 horas. Alguns desses valores são próximos dos encontrados, outros são extremamente diferentes, mesmo considerando gramíneas de clima temperado que de certa forma é esclarecido por Keyserlingk (1996) que relacionou as variações entre forrageiras.

O fornecimento de suplemento concentrado poderia levar a um efeito associativo, mudando o desaparecimento da FDN no rúmen, tanto positiva como negativamente. Conforme Dixon \& Stockdale (1999) o efeito associativo positivo, na maioria das vezes, ocorre quando há um nutriente limitante para os microrganismos do rúmen (nitrogênio), geralmente observado em uma forrageira de baixa ou média qualidade, e tendo o suplemento uma concentração deste nutriente que atenda esta exigência. Ao contrário, tendo a forrageira uma qualidade de média para boa, o fornecimento de suplementos ricos em energia poderia gerar um tipo de interação com os microrganismos que tivesse um efeito negativo sobre o desaparecimento da fibra. Porém, neste ensaio não foi observado nenhum tipo de efeito.

\section{Conclusões}

Os suplementos, nas quantidades fornecidas, não influenciaram o $\mathrm{pH}$ do liquido ruminal, entretanto, aqueles com maior degradabilidade da proteína, e quando fornecidos em maiores quantidades, proporcionaram maiores níveis de $\mathrm{N}-\mathrm{NH}_{3}$ ruminal. Já o desaparecimento da FDN da forrageira não foi afetado por qualquer tratamento imposto.

\section{Literatura Citada}

AFRC. Energy and protein requirements of ruminant. Farnham Royal: CAB, 1993. 159p.

COELHO DA SILVA, J.F.; LEÃO, M.I. Fundamentos de nutrição dos ruminantes. Piracicaba: Livroceres. 1979. $380 \mathrm{p}$.

CATON, J.S.; FREEMAN, A.S.; GALYEAN, M.L. Influence of protein supplementation on forage intake, in situ forage

R. Bras. Zootec., v.31, n.6, p.2340-2349, 2002 disappearance, ruminal fermentation and digesta passage rates in steers grazing dormant blue grama rangelands. Journal of Animal Science, v.66, n.9, p.22622271, 1988.

COCHRAN, R.C.; KÖSTER, K.C.; OLSON, J.S. et. al. Supplemental protein for grazing cattle examined. Feedstuffs, v.70, n.7, p.12-19, 1998.

DIXON, R.M.; STOCKDALE, C.R. Associative effects between forages and grains: consequences for feed utilization. Australian Journal Agricultural Research, v.50, n.5, p.757-773, 1999.

EUCLIDES, V.B.P.; MACEDO, M.C.M.; OLIVEIRA, M.P. Avaliação de diferentes métodos de amostragem para estimar o valor nutritivo de forragens sob pastejo. Revista da Sociedade Brasileira de Zootecnia, v.21, n.4, p.691-702, 1992.

FRANCO, A.V.M.; FRANCO, G.L.; ANDRADE, P. Efeito da degradabilidade da proteína e níveis de suplementação sobre os parâmetros ruminais pH e N-NH . In: REUNIÃ̃O ANUAL DA SOCIEDADE BRASILEIRA DE ZOOTECNIA, 33., 1996, Fortaleza. Anais... Fortaleza: Sociedade Brasileira de Zootecnia, 1996. p.333-334.

GALYEAN, M.L; OWENS, F.N. Effects of diet composition and level of feed intake on site and extent of digestion in ruminants. In: TSUDA, T.; SASAKI, Y.; KAWASHIMA, R. (Eds.). Physiological aspects of digestion and metabolism in ruminants. New York: Academic Press, 1991. p.483-514.

GIERUS, M.; CIOCCA, M.L.; MÜHLBACH, P.R.F. Utilização de farelo de soja como suplemento protéico para palha de trigo tratada com $\mathrm{NaOH}$. II Degradabilidade ruminal da matéria seca e níveis de amônia. In: REUNIÃO ANUAL DA SOCIEDADE BRASILEIRA DE ZOOTECNIA, 32., 1995. Brasília. Anais... Brasília: Sociedade Brasileira de Zootecnia, 1995. p.332-333.

GUPTA, B.K.; MULTANI, K.K.; AHUJA, A.K. et al. In sacco degradability of dry matter, crude protein and cell wall of various forages. Indian Journal Animal Science, v.66, n.9, p.924-929, 1996.

HESS, B.W.; PARK, K.K.; KRYSL, M.B. et al. Supplemental protein for beef cattle grazing dormant intermediate wheatgrass pasture: effects on nutrient quality, forage intake, digesta kinetics, grazing behavior, ruminal fermentation, and digestion. Journal of Animal Science, v.72, n.8, p.2213-2223, 1994.

HUNGATE, R.E. The rumen and its microbes. 2.ed. London: Academic Press, 1966. 533p.

HUNT, C.W.; PARKINSON, J.F.; ROEDER, R.A. et al. The delivery of cottonseed meal at three different time intervals to steers fed low-quality grass hay: effects on digestion and performance. Journal of Animal Science, v.67, n.5, p.1360-1366, 1989.

HUNTINGTON, J.A.; GIVENS, D.I. The in situ technique for studying the rumen degradation of feeds: a review of the procedure. Nutrition Abstracts Review, v.65, n.2, p.63-93, 1995.

JUDKINS, M.B.; KRYSL, L.J.; BARTON, D.W. et al. Effects of cottonseed meal supplementation time on ruminal fermentation and forage intake by Holstein steers fed fescue hay. Journal of Animal Science, v.69, n.9, p.3789-3797, 1991.

KEYSERLINGK, M.G.A.; SWIFT, M.L.; PUCHALA, R. et al. Degradability characteristics of dry matter and crude protein of forages in ruminants. Animal Feed Science and Technology, v.57, n.4, p.291-311, 1996. 
KRYSL, L.J.; BRANINE, M.E.; CHEEMA, A.U. et al. Influence of soybean and sorghum grain supplementation on intake, digesta kinetics, ruminal fermentation, site and extent of digestion and microbial protein synthesis in beef steers grazing blue grama rangeland. Journal of Animal Science, v.67, n.11, p.3040-3051, 1989.

McCOLLUM, F.T.; GALYEAN, M.L. Influence of cottonseed meal supplementation on voluntary intake, rumen fermentation and rate of prairie hay in beef steers. Journal of Animal Science, v.60, n.2, p.570-573, 1985.

MEHREZ, A.Z.; ØRSKOV, E.R.; McDONALD, I. Rates of rumen fermentation in relation to ammonia concentration. British Journal Nutrition, v.38, n.3, p.437-443, 1977.

MORRISON, M.; MACKIE, R.I. Nitrogen metabolism by ruminal microorganisms: current understanding and future perspectives. Australian Journal Agricultural Research, v.47, n.2, p.227-246, 1996.

ØRSKOV, E.R.; TYLE, M. Energy nutrition in ruminants. Cambridge: Elsevier Science Publishers. 1990. 146p.

ORTIGNES, I.; FONTENOT, J.P.; FERRY, J.G. Digesta flows in sheep fed poor-quality hay supplemented with urea and carbohydrates. Journal of Animal Science, v.66, n.4, p.975-985, 1988.

OWENS, F.N.; ZINN, R. Metabolismo de la proteína en los rumiantes. In: CHURCH, D.C. (Ed.) El rumiante: fisiológia digestiva e nutricíon. Zaragoza: Acribia. 3.ed. 1988. p.255281.

PAULINO, M.F.; ARRUDA, M.L.R.; RUAS, J.R.M. et. al. Efeito do farelo de trigo em substituição ao milho desintegrado com palha e sabugo, em suplementos múltiplos, sobre o desenvolvimento de bezerros Nelore em pastoreio. In: REUNIÃO ANUAL DA SOCIEDADE BRASILEIRA DE ZOOTECNIA, 32., 1995, Brasília. Anais... Brasília: Sociedade Brasileira de Zootecnia, 1995. p.250-251.

SAS INSTITUTE. User's guide: Statistics. 5.ed. v.1. Cary: 1985. p.956.
SATTER, L.D.; ROFFLER, R.E. Nitrogen requirement and utilization in dairy cattle. Journal of Dairy Science, v.58, n.8, p.1212-1237, 1979.

SPRAG, J.C.; KELLAWAY, R.C.; LEIBHOLZ, J. Effects of supplement on intake, rumen function, and nutrient supply and growth in cattle eating alkali-treated oat straw. British Journal Nutrition, v.56, n.2, p.487-495, 1996.

STOKES, S.R.; GOETACH, A.L.; LANDIS, K.L. et al. Feed intake and digestion by beef cows fed prairie hay with different levels of soybean meal and receiving post ruminal administration of antibiotics. Journal of Animal Science, v.66, n.7, p.1778-1789, 1988.

VIEIRA, P.F. Efeito do formaldeído na proteção de proteínas e lipídeos em ração para ruminantes. Viçosa, MG: Universidade Federal de Viçosa, 1980. 98p. Tese (Doutorado em Zootecnia) - Universidade Federal de Viçosa, 1980.

Van SOEST, P.J. Nutritional ecology of the ruminant. 2.ed. Ithaca: Cornell University Press, 1994. 476p. 